\title{
Parodontitis vorbeugen und therapieren
}

Der Vorstand der Deutschen Gesellschaft für Parodontologie (DG PARO) hatte im Oktober Gesundheitspolitiker, Wissenschaftler sowie Vertreter der Zahnärzte, Krankenkassen und Patienten zum Parlamentarischen Abend nach Berlin eingeladen. Gemeinsam diskutierten die Teilnehmer auf Grundlage exzellenter Fachvorträge über Möglichkeiten, die Volkskrankheit Parodontitis effektiv zu bekämpfen. In der Diskussion kristallisierten sich 4 Ansatzpunkte heraus: bessere Verankerung der Parodontologie in Zahnärzteausund -fortbildung, höhere Behandlungsvergütung sowie Maßnahmen zur konsequenteren Patienten-Compliance. Dirk Heidenblut als Vertreter der Regierungskoalition versprach, auch weiterhin konsequent auf Prävention zu setzen und die

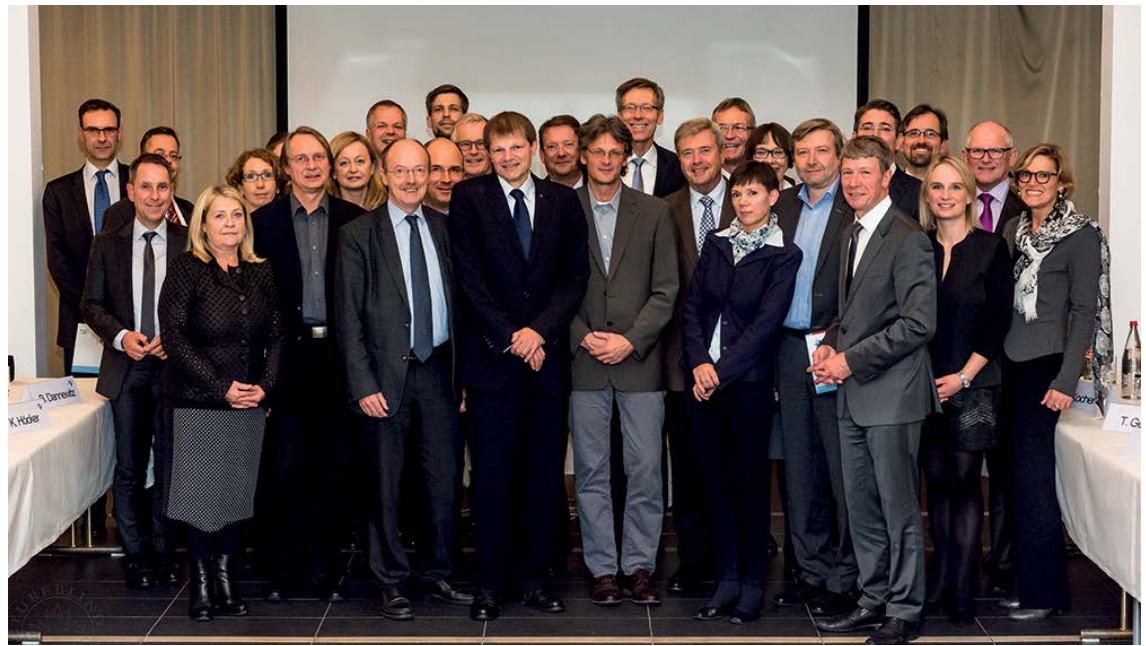

Öffentlichkeitsarbeit der Fachgesellschaf-

Nach einer Pressemitteilung des Deutsche Gesellschaft für Parodontologie e.V., Regensburg www.dgparo.de 